\title{
Constitutive Accumulation of a Resveratrol-Glucoside in Transgenic Alfalfa Increases Resistance to Phoma medicaginis
}

\author{
John D. Hipskind and Nancy L. Paiva \\ The Samuel Roberts Noble Foundation, P.O. Box 2180, 2510 Sam Noble Parkway, Ardmore, OK 73402, \\ U.S.A. \\ Accepted 14 January 2000.
}

\begin{abstract}
Alfalfa (Medicago sativa) was transformed with a peanut (Arachis hypogaea) cDNA encoding resveratrol synthase (RS) transcriptionally regulated by an enhanced Cauliflower mosaic virus (CaMV) $35 \mathrm{~S}$ promoter. Transgenic plants accumulated a new compound, not present in wildtype or vector-transformed alfalfa, that was identified as trans-resveratrol-3- $\boldsymbol{O}$ - $\beta$-D-glucopyranoside (RGluc) by high-pressure liquid chromatography (HPLC), UV, ${ }^{1} \mathrm{H}$ and ${ }^{13} \mathrm{C}$-nuclear magnetic resonance (NMR) analyses. RGluc concentration was highest in the youngest leaves (>15 $\mu \mathrm{g}$ per $\mathrm{g}$ fresh weight) and oldest stem internode segments ( $>10 \mu \mathrm{g}$ per $\mathrm{g}$ fresh weight) while roots contained only trace amounts $(<0.2 \mu \mathrm{g}$ per $\mathrm{g}$ fresh weight $)$. RS transcript levels were highest in leaves and stems, with comparatively little transcript accumulation in the roots, while an inverse pattern was observed for chalcone synthase (CHS) transcript levels. CHS directly competes with RS for the metabolic precursors $p$-coumaroyl CoA and malonyl CoA, and may also contribute to the developmental variations in RGluc levels by limiting the availability of substrates. Agar-plate bioassays indicated that both RGluc and resveratrol greatly inhibit hyphal growth of the alfalfa fungal pathogen Phoma medicaginis. Subsequently, RGluc-containing leaves were wound inoculated and showed a significant reduction (relative to control leaves) in the size of necrotic lesions, intensity of adjacent chlorosis, and number of fungal reproductive structures (pycnidia). Decreasing sporulation of this pathogen may greatly reduce disease spread and severity throughout the field.
\end{abstract}

Additional keywords: disease resistance, phytoalexin, secondary metabolism, stilbene.

Genetic engineering of plant secondary metabolism offers the opportunity to develop transgenic plants with increased commercial, agricultural, or pharmacological value. One such pathway with potential for manipulation is phenylpropanoid metabolism, whereby derivatives of cinnamic acid are con-

Corresponding author: Nancy L. Paiva; Telephone: 580-223-5810; Fax: 580-221-7380; E-mail: nlpaiva@noble.org

Present address of John D. Hipskind: Novartis (NABRI), 3054 Cornwallis Rd, P.O. Box 12257, Research Triangle Park, NC 27709, U.S.A. verted to a wide array of phenolic compounds necessary for plant growth, development, or active responses to biotic and abiotic stress (Dixon and Paiva 1995; Hahlbrock and Scheel 1989). Such experiments to alter this pathway might include sense or antisense overexpression of biosynthetic structural genes, transcriptional regulators, and the introduction of heterologous genes to synthesize novel compounds or chemically alter endogenous metabolites. For example, constitutive expression of an alfalfa caffeic acid 3- $O$-methyltransferase antisense RNA resulted in reduced lignin in transgenic tobacco, demonstrating the potential for improved commercial processing and forage biomass digestibility (Ni et al. 1994). More recently, it was reported that constitutive ectopic expression of a transcriptional regulator of flavonoid metabolism could alter both the phenylpropanoid and flavonoid metabolic pathways, resulting in the novel accumulation of secondary metabolites (Grotewold et al. 1998).

One specific class of phenolics that has significant potential for transgenic manipulation are the stilbenes. These widely distributed phenolics have been isolated from a number of diverse plant families including grape (Vitaceae), Scots pine (Cyperaceae), peanut (Leguminosae), and tall fescue (Poaceae) (Sotheeswaran and Pasupathy 1993; Powell et al. 1994). The initial step in the biosynthesis of these compounds is through the condensation of one molecule of $p$-coumaroyl $\mathrm{CoA}$ and three molecules of malonyl CoA by resveratrol synthase (RS) (E.C. 2.3.1.95) to form trans-3, 5, 4'-trihydroxystilbene, commonly known as resveratrol (Rolfs and Kindl 1984). Following the synthesis of resveratrol, conjugation to sugars or other derivatizations may occur, including methylation, prenylation, or condensation reactions to form speciesspecific dimers, trimers, or tetramers (Sotheeswaran and Pasupathy 1993). RSs are related to chalcone synthases (CHSs) that catalyze the first committed step of flavonoid metabolism by the condensation of substrates through a polyketide intermediate (Lanz et al. 1990). However, the ring closure required for the formation of the stilbene carbon backbone involves an additional decarboxylation reaction. A phylogenetic comparison of $R S$ and $C H S$ genes revealed that $R S$ genes do not form a separate cluster, but are instead most closely related to the $C H S$ from the same or related plant species (Tropf et al. 1994). In addition, site-directed mutagenesis of as few as three amino acids was sufficient to convert CHS enzyme activity to RS. These data suggest that $R S$ genes most 
likely evolved independently in each plant species from an endogenous $\mathrm{CHS}$.

The constitutive accumulation of stilbenes is believed to act as a general mechanism of antimicrobial disease resistance while in some plant species resveratrol accumulates as a phytoalexin following microbial attack (Langcake and Pryce 1976; Dercks et al. 1995). In addition, several members of the stilbenoids, including resveratrol, are believed to play a significant role in the pharmacological activity of medicinal plants through antileukaemic, antioxidant, or chemopreventive activities (Mannila et al. 1993; Rice-Evans et al. 1997; Jang et al. 1997). Genetic engineering to express $\mathrm{RS}$ in heterologous plant species is considered an attractive option because the synthesis of resveratrol as a foreign phytoalexin requires the addition of only a single gene. Transformation of tobacco with an $R S$ genomic clone from peanut resulted in the rapid accumulation of resveratrol following treatment of cell suspension cultures with fungal elicitor (Hain et al. 1990). Subsequently, experiments with an $R S$ gene (Vst1) from Vitis vinifera L. demonstrated a significant level of resistance in transgenic tobacco, tomato, and rice to fungal pathogens Botrytis cinerea, Phytophthora infestans, and Pyricularia oryzae, respectively (Hain et al. 1993; Thomzik et al. 1997; Stark-Lorenzen et al. 1997). These reports demonstrate that the expression of an $R S$ gene in a foreign plant species may offer a broad spectrum of increased resistance to fungal pathogens. However, little phytochemical analysis of these transgenic plants has been carried out, and negative effects, including male sterility and flower color loss, have been reported when high levels of RS were constitutively expressed in tobacco (Fischer et al. 1997).

In the present investigation, we have transformed alfalfa (Medicago sativa L.) with an RS cDNA from peanut (Arachis hypogaea) (Tropf et al. 1994) under the transcriptional regulation of an enhanced Cauliflower mosaic virus (CaMV) 35S promoter (Restrepo et al. 1990). Alfalfa is an important forage crop that is not known to accumulate stilbenes but does accumulate significant levels of flavonoids and isoflavonoids; thus, the necessary substrates for RS should be present (Paiva et al. 1994; Sumner et al. 1996). Following Agrobacterium-mediated transformation, we have observed the constitutive accumulation of a resveratrol derivative, positively identified by high-pressure liquid chromatography (HPLC), UV, ${ }^{1} \mathrm{H}$ - and ${ }^{13} \mathrm{C}$-nuclear magnetic resonance (NMR) analyses as trans-resveratrol-3- $O-\beta-\mathrm{D}-$ glucopyranoside (RGluc) (Fig. 1). To our knowledge, this is the first report of this compound accumulating in any transformed plant species expressing RS activity. Despite high levels of RGluc accumulation (up to $20.0 \mu \mathrm{g}$ per gram fresh weight in leaves), no visible phenotype was observed. Leaves of independent lines accumulating the highest levels of the resveratrol conjugate were wound inoculated with the alfalfa fungal pathogen Phoma medicaginis, the causal agent of spring black stem and leaf spot disease (Leath 1990). Results show that the area of leaf necrosis surrounding the site of inoculation is reduced by as much as $50 \%$ at 10 days post inoculation, compared with vector control plants. In addition, the amount of hyphal ingress beyond this necrotic lesion was dramatically reduced, as was the subsequent formation of reproductive structures known as pycnidia. These results suggest that the constitutive accumulation of RGluc in alfalfa may decrease yield loss by limiting disease in the primary infection and the secondary spread of the pathogen.

\section{RESULTS}

\section{Phytochemical characterization of transgenic alfalfa expressing RS.}

Polymerase chain reaction (PCR) and Southern blot analyses were used to identify independent transgenic alfalfa lines harboring the CaMV 35S:RS construct (Fig. 2; see Materials and Methods). Individual lines were analyzed by HPLC for the constitutive accumulation of resveratrol. Results shown in Figure 3A reveal the presence of an unknown peak $(8.2 \mathrm{~min})$ that appears only in the leaves and internodes of lines transformed with the CaMV 35S:RS binary vector (chromatogram a) and not vector control plants (chromatogram b). The UV spectra of the 8.2-min peak and a resveratrol standard are nearly identical with two absorbance maxima of 307 and $320 \mathrm{~nm}$ for both compounds (Fig. $3 \mathrm{~B})$. However, the $8.2-\mathrm{min}$ retention time is significantly less than the retention time observed with a resveratrol standard (14.9 $\mathrm{min})$. This result suggested that the resveratrol had

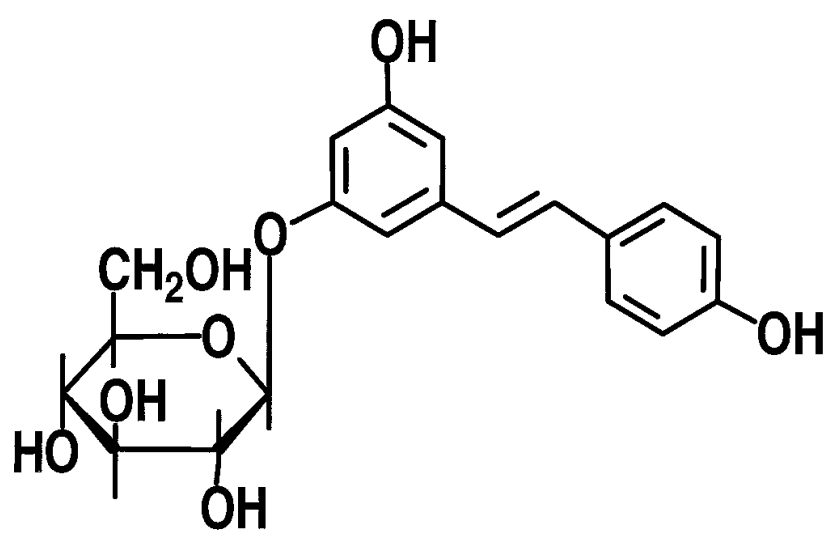

Fig. 1. The structure of trans-resveratrol-3-O- $\beta$-D-glucopyranoside (RGluc).

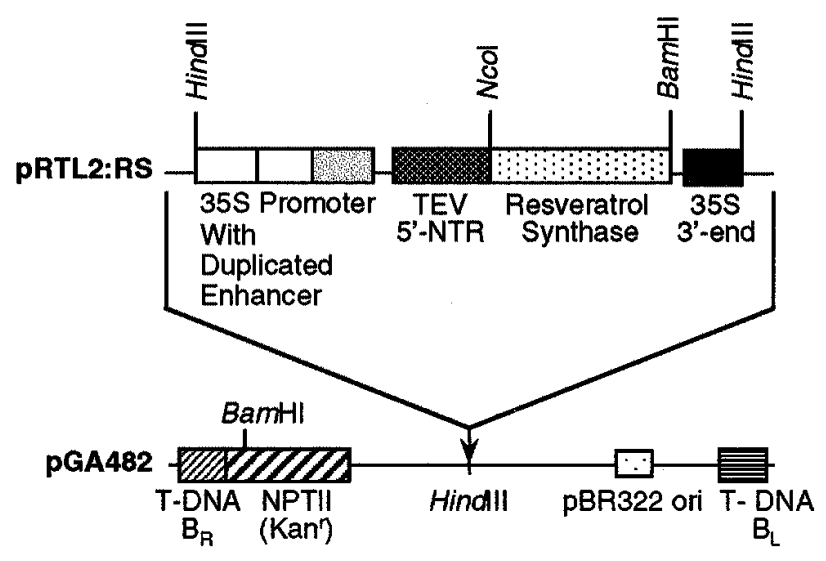

Fig. 2. Duplicated enhancer Cauliflower mosaic virus (CaMV) 35S:RS (resveratrol synthase) binary vector containing an RS cDNA from peanut. 

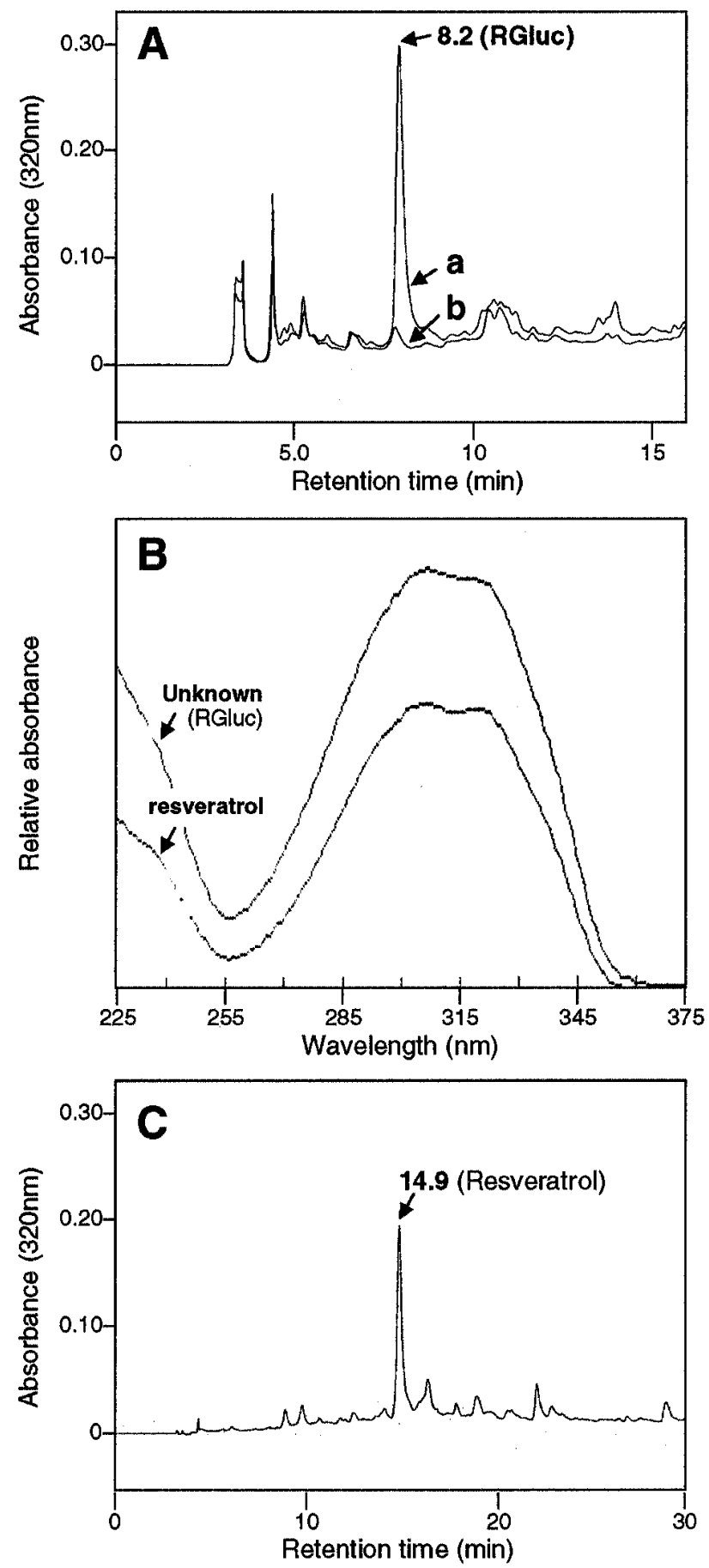

Fig. 3. Phytochemical analysis of transgenic alfalfa lines. A, Reversephase $\mathrm{C} 18$ high-pressure liquid chromatography (HPLC) analysis of crude acetone extracts revealing an unknown metabolite at $8.2 \mathrm{~min}$ in the Cauliflower mosaic virus (CaMV) 35S:RS (resveratrol synthase) transformed alfalfa line (chromatogram a) that is not present in a pGA482 binary vector control plant (chromatogram b). B, UV absorbance spectra of the unknown compound compared with a known resveratrol standard. C, HPLC analysis of the putative resveratrolconjugate following treatment with $\beta$-glucosidase revealing the release of the resveratrol aglycone, eluting at 14.9 min. Identity was confirmed by co-chromatography with an authentic resveratrol standard. been modified by the addition of hydrophilic moiety, possibly a sugar. Hydrolysis with $\beta$-glucosidase of the unknown compound results in the appearance of free resveratrol (Fig. $3 \mathrm{C})$. In addition, removal of $\mathrm{H}_{3} \mathrm{PO}_{4}$ from the aqueous phase of the HPLC solvent system did not alter the retention time of the resveratrol conjugate(data not shown). This observation suggested that the sugar moiety was not substituted with a charged group such as malonic acid. Subsequently, data obtained from ${ }^{13} \mathrm{C}$-NMR and ${ }^{1} \mathrm{H}-\mathrm{NMR}$ (Tables 1 and 2, respectively) closely matched previous reported values for trans-resveratrol-3-O- $\beta$-glucopyranoside (Fig. 1), commonly known as piceid or polydatin (Waterhouse and Lamuela-Raventóst 1994; Mattivi et al. 1995; Teguo et al. 1996).

Table 1. Comparison of ${ }^{13} \mathrm{C}-\mathrm{NMR}$ (nuclear magnetic resonance) chemical shift values $\left(150 \mathrm{MHz}, \mathrm{CD}_{3} \mathrm{OD}\right)$ for the isolated resveratrol conjugate with values from two published studies

\begin{tabular}{cccc}
\hline $\mathbf{C}^{\mathbf{a}}$ & $\delta \mathbf{( R G l u c}^{\mathbf{b}}$ & $\delta^{\mathbf{c}}$ & $\delta^{\mathbf{d}}$ \\
\hline Resveratrol & & & \\
1 & 141.43 & 141.4 & 140.9 \\
2 & 107.05 & 107.0 & 106.2 \\
3 & 160.47 & 160.5 & 160.2 \\
4 & 104.13 & 104.1 & 103.9 \\
5 & 159.58 & 159.6 & 159.4 \\
6 & 108.38 & 108.4 & 108.2 \\
7 & 126.69 & 126.7 & 126.5 \\
8 & 129.99 & 130.0 & 129.9 \\
$1^{\prime}$ & 130.34 & 130.3 & 130.0 \\
$2^{\prime}, 6^{\prime}$ & 128.91 & 128.9 & 128.9 \\
$3^{\prime}, 5^{\prime}$ & 116.50 & 116.5 & 116.4 \\
$4^{\prime}$ & 158.47 & 158.5 & 158.2 \\
Glucose & & & \\
$1^{\prime \prime}$ & 102.43 & 102.4 & 102.1 \\
$2^{\prime \prime}$ & 74.97 & 75.0 & 74.8 \\
$3^{\prime \prime}$ & 78.07 & 78.1 & 78.1 \\
$4^{\prime \prime}$ & 71.51 & 71.5 & 71.5 \\
$5^{\prime \prime}$ & 78.25 & 78.3 & 77.8 \\
$6^{\prime \prime}$ & 62.62 & 62.6 & 62.8 \\
\hline
\end{tabular}

${ }^{\text {a }}$ Carbon assignments as reported by Mattivi et al.

${ }^{\mathrm{b}}$ RGluc $=$ trans-resveratrol-3-O- $\beta$-D-glucopyranoside.

${ }^{c}$ Values reported by Teguo et al. (1996).

${ }^{\mathrm{d}}$ Values reported by Mattivi et al. (1995).

Table 2. Comparison of ${ }^{1} \mathrm{H}-\mathrm{NMR}$ (nuclear magnetic resonance) chemical shift values $\left(600 \mathrm{MHz}, \mathrm{CD}_{3} \mathrm{OD}\right.$ ) for the isolated resveratrol conjugate with published values

\begin{tabular}{lll}
\hline Proton assignment $^{\mathbf{a}}$ & \multicolumn{1}{c}{$\delta$ (RGluc) $^{\mathbf{b}}$} & \multicolumn{1}{c}{$\delta^{\mathbf{c}}$} \\
\hline $\mathrm{H}-2^{\prime}, \mathrm{H}-6^{\prime}$ & $7.35(2 \mathrm{H}, \mathrm{d})^{\mathrm{d}}$ & $7.35(2 \mathrm{H}, \mathrm{d})$ \\
$\mathrm{H}-8$ & $7.01(1 \mathrm{H}, \mathrm{d})$ & $7.00(1 \mathrm{H}, \mathrm{d})$ \\
$\mathrm{H}-7$ & $6.84(1 \mathrm{H}, \mathrm{d})$ & $6.84(1 \mathrm{H}, \mathrm{d})$ \\
$\mathrm{H}-2$ & $6.78(1 \mathrm{H}, \mathrm{br} \mathrm{s})$ & $6.78(1 \mathrm{H}, \mathrm{br} \mathrm{s})$ \\
$\mathrm{H}-3^{\prime}, \mathrm{H}-5^{\prime}$ & $6.76(2 \mathrm{H}, \mathrm{d})$ & $6.76(2 \mathrm{H}, \mathrm{d})$ \\
$\mathrm{H}-6$ & $6.61(1 \mathrm{H}, \mathrm{br} \mathrm{s})$ & $6.61(1 \mathrm{H}, \mathrm{br} \mathrm{s})$ \\
$\mathrm{H}-4$ & $6.45(1 \mathrm{H}, \mathrm{br} \mathrm{s})$ & $6.44(1 \mathrm{H}, \mathrm{br} \mathrm{s})$ \\
Glc H-1" & $4.89(1 \mathrm{H}, \mathrm{d})$ & $4.88(1 \mathrm{H}, \mathrm{d})$ \\
Glc H-6a" & $3.92(1 \mathrm{H}, \mathrm{dd})$ & $3.92(1 \mathrm{H}, \mathrm{dd})$ \\
Glc H-6b" & $3.71(1 \mathrm{H}, \mathrm{dd})$ & $3.70(1 \mathrm{H}, \mathrm{dd})$ \\
Glc H-2", H-3", H-4", H-5" & $3.48-3.38(4 \mathrm{H}, \mathrm{m})$ & $3.48-3.38(4 \mathrm{H}, \mathrm{m})$
\end{tabular}

${ }^{a}$ Proton assignments as reported by Teguo et al. (1996).

${ }^{\mathrm{b}}$ RGluc $=$ trans-resveratrol-3-O- $\beta$-D-glucopyranoside.

${ }^{c}$ Values reported by Teguo et al. (1996).

d Peak descriptions: d, doublet; brs, broad singlet, dd, doublet of doublets; m, multiplet. 
Developmental variation in the accumulation of RGluc.

In preliminary experiments, HPLC analyses of whole shoots collected from independent, transgenic, alfalfa lines revealed that the concentration of RGluc ranged from 0.5 to $20.0 \mu \mathrm{g}$ per gram fresh weight, measured as resveratrol equivalents. However, these data were significantly variable for replicate samples taken from the same independent lines. Therefore, an experiment was performed to test whether the concentration of the RGluc varied with developmental stage or tissue type. Independent alfalfa lines that showed consistently high levels of RGluc were grown under greenhouse conditions. The leaves and internodes from several shoots were harvested, pooled, and extracted for HPLC analysis according to their relative age and position on individual alfalfa shoots; for example, L-1 was considered the youngest leaf (Fig. 4). Results show that the concentration of RGluc in the leaves declines significantly from the youngest to the oldest leaves on a $\mu \mathrm{g}$ per gram fresh weight basis (Fig. 5A). In contrast, the concentration increases significantly from the youngest internodes to the oldest. Similar results were obtained in two additional RGluc-accumulating lines (data not shown). Unglycosylated resveratrol was

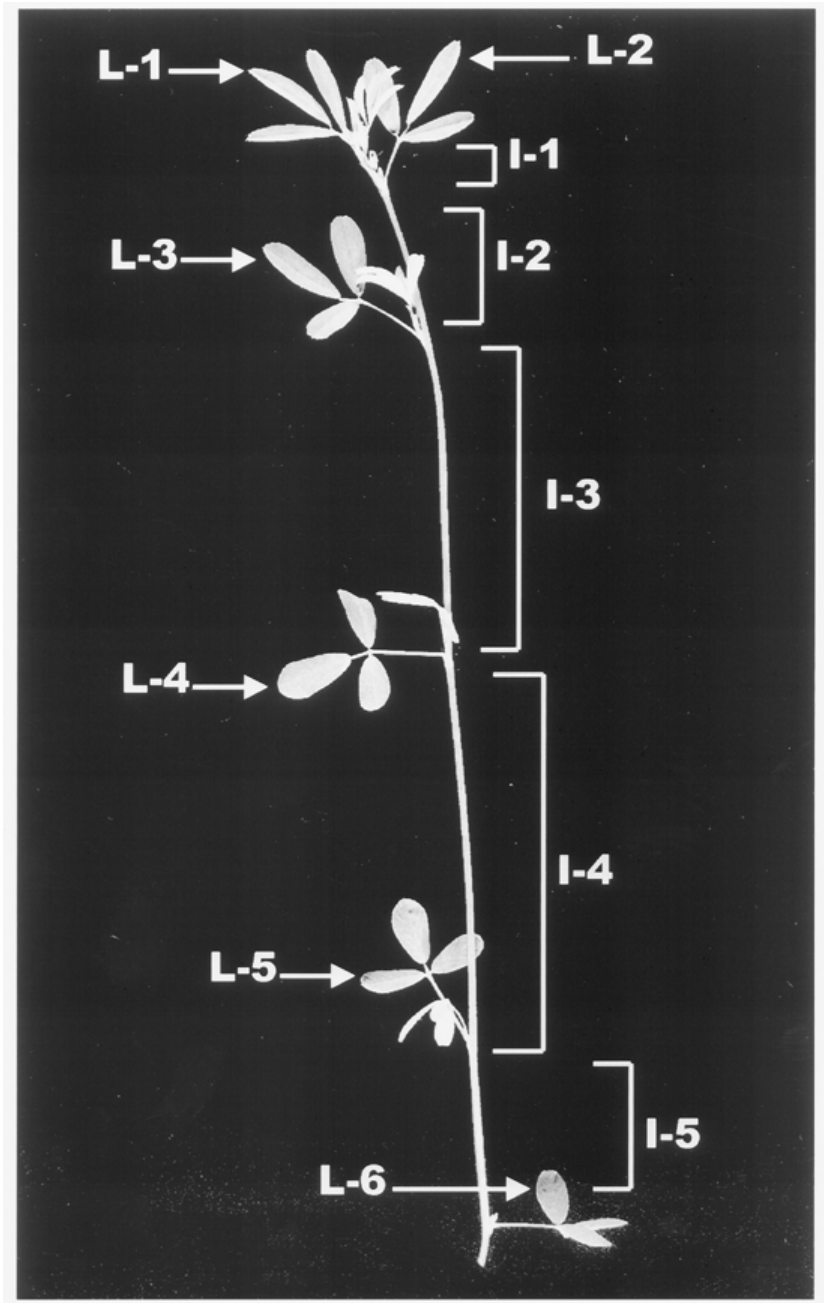

Fig. 4. Leaf and internode designations used in the analysis of Cauliflower mosaic virus (CaMV) 35S:RS (resveratrol synthase) transformed alfalfa lines ( $\mathrm{L}=$ leaves; $\mathrm{I}=$ internodes $)$. never detected in any of the alfalfa tissue extracts. Northern (RNA) blot analyses taken from the same independent line indicate that the relative levels of RS transcripts were not significantly affected by the tissue or age type (Fig. 5B). Taken together, these data suggest there is no correlation between RS transcript levels and extractable levels of RGluc in these tissues. The apparent decrease in RGluc in older leaves may be due to biological or photochemical degradation, or due to leaf expansion and increase in leaf mass, or a combination of these factors.

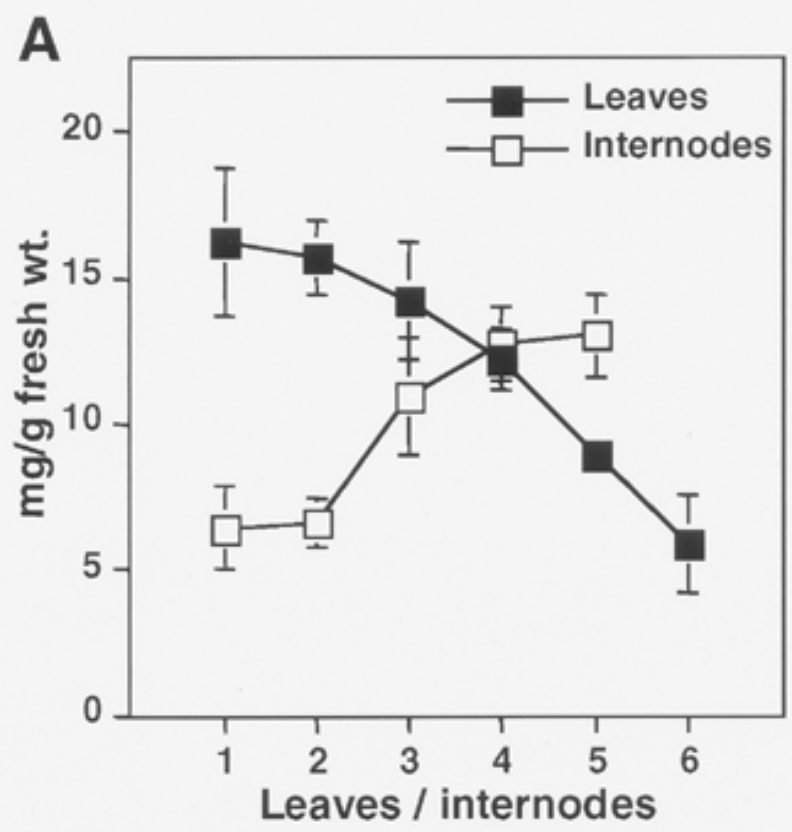

B
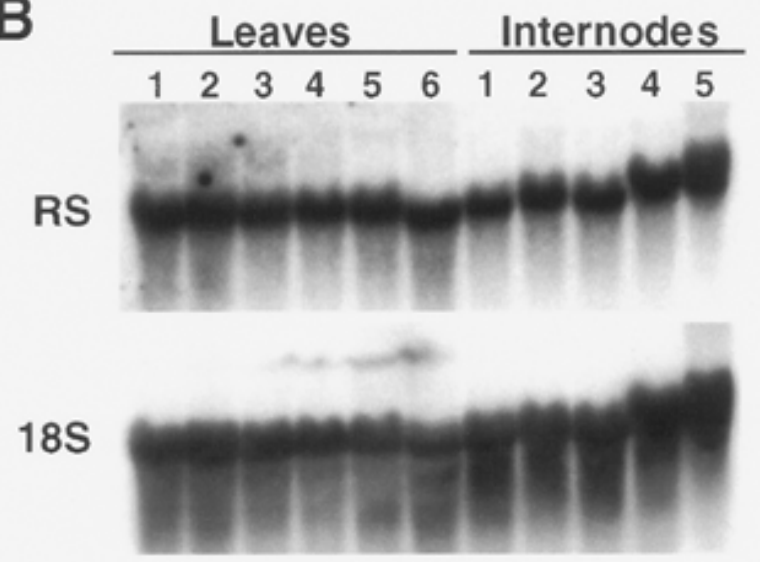

Fig. 5. Developmental and tissue specific accumulation of transresveratrol-3-O- $\beta$-D-glucopyranoside (RGluc) and resveratrol synthase (RS) transcripts. A, Results from high-pressure liquid chromatography (HPLC) analysis of leaves and internodes along shoots from a Cauliflower mosaic virus (CaMV) 35S:RS transformed line revealing the age-dependent accumulation of RGluc. (See Figure 4 for numbering system.) Data represent an average of three replicate samples; error bars equal to the standard deviation of the mean. RGluc values are expressed as resveratrol equivalents. B, RS transcript levels in leaves and internodes relative to age or tissue type (total RNA $=10$ $\mu \mathrm{g}$ per lane). A soybean $18 \mathrm{~S}$ ribosomal RNA clone served as a loading control probe. 

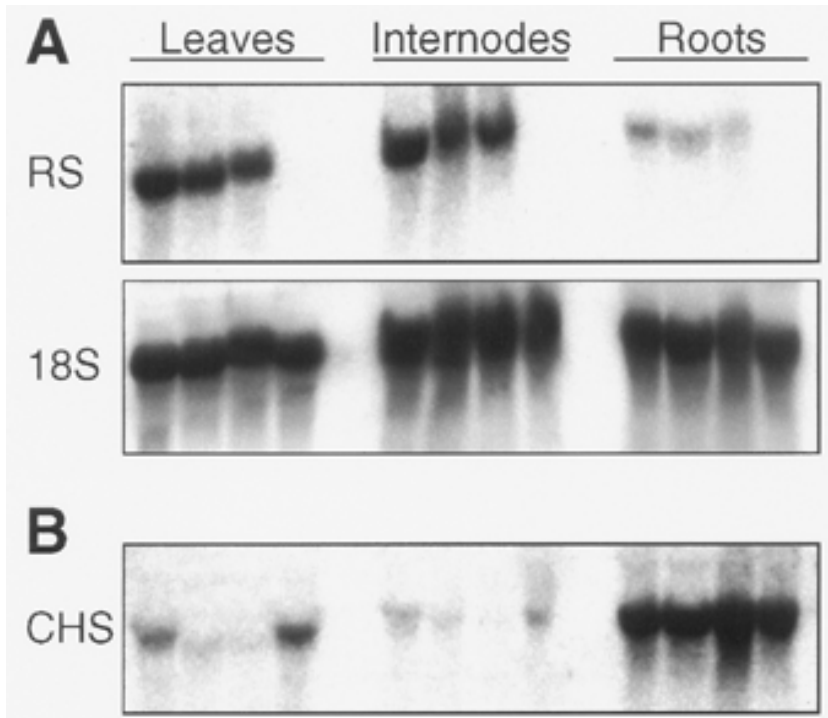

$18 \mathrm{~S}$

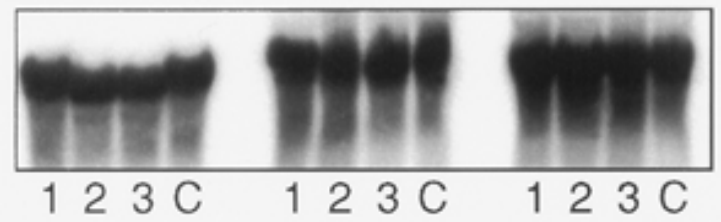

Fig. 6. Comparison of resveratrol synthase (RS) to chalcone synthase (CHS) transcript levels in the leaves, internodes and roots. A, RS transcript levels in RNA (total RNA $=10 \mu \mathrm{g}$ per lane) extracted from leaves, internodes, and roots of three independently transformed alfalfa lines (lanes 1-3) and one control line ( $\mathrm{C}=$ pGA482 vector control plant). B, The same total RNA preparations hybridized with an alfalfa CHS cDNA probe. $\mathbf{A}$ and $\mathbf{B}$, In both experiments blots were rehybridized with a soybean $18 \mathrm{~S}$ ribosomal RNA probe as a loading control.

\section{Comparison of RS and CHS transcript levels in leaves, internodes, and roots.}

High levels of RGluc accumulate in the young leaves (approximately $15.0 \mu \mathrm{g}$ per $\mathrm{g}$ fresh weight) and the old internodes (approximately $13.0 \mu \mathrm{g}$ per $\mathrm{g}$ fresh weight) of the highest accumulating alfalfa lines expressing RS. However, roots contained only marginal levels of RGluc $(<0.2 \mu \mathrm{g}$ per $\mathrm{g}$ fresh weight) in these same independent lines (data not shown). Alfalfa roots are known to accumulate high constitutive levels of flavonoids and isoflavonoids (Paiva et al. 1991; Sumner et al. 1996), and CHS would compete directly with RS for the metabolic intermediates $p$-coumaroyl CoA and malonyl CoA. Therefore, Northern blot experiments were performed to compare the relative transcript levels of $\mathrm{RS}$ and CHS in the leaves, internodes, and roots of three independent CaMV 35S:RS lines and a vector control line. Results in Figure 6A show that the highest levels of RS transcripts are found in the leaves and internodes while comparatively low levels were detected in the roots (lanes 1-3). As expected, no RS transcripts were detected in the vector control (lane C). In contrast, the highest CHS message levels were detected in the roots, compared with the leaves and internodes (Fig. 6B). The nearly undetectable levels of RGluc in the roots may therefore be due to a combination of relatively low RS transcript levels and strong competition for the available substrate pool by high levels of CHS. The use of promoters with stronger root expression in alfalfa may eventually allow higher levels of RGluc expression.

\section{Sensitivity of Phoma medicaginis to RGluc in agar-plate bioassays and transgenic plant infection studies.}

Prior to the transformation experiments, agar-plate bioassays were used to test free resveratrol for antifungal activity against several alfalfa pathogens (See Materials and Methods). Results showed that the mycelial growth of an isolate

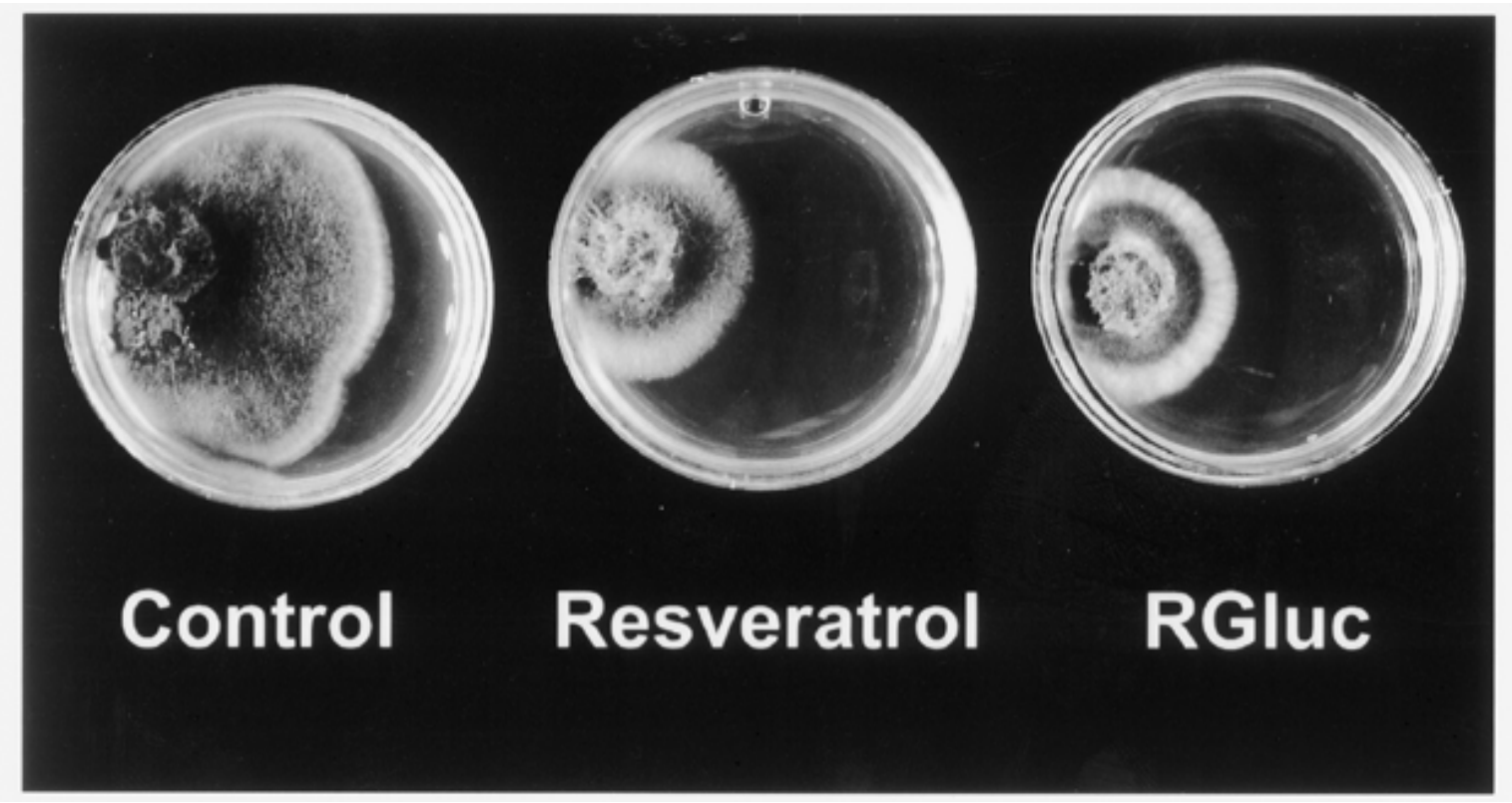

Fig. 7. Representative agar-plate bioassay of resveratrol and trans-resveratrol-3- $O$ - $\beta$-D-glucopyranoside (RGluc) to determine their relative ability to inhibit hyphal growth of alfalfa fungal pathogen Phoma medicaginis. Control = ethanol; RGluc and resveratrol = $50 \mu \mathrm{g}$ (resveratrol equivalents) per $\mathrm{ml}$ of agar. 
of Phoma medicaginis was greatly inhibited. RGluc was purified by preparative HPLC from transgenic lines and tested in agar-plate bioassays in order to assess its effectiveness against this same isolate. At a concentration of $50 \mu \mathrm{g}$ (resveratrol equivalents)/ml, hyphal growth was approximately equally reduced $(>50 \%)$ in the presence of RGluc or resveratrol (Fig. 7). Three replicates of this experiment were performed. Importantly, the concentration of RGluc in young leaves of the transgenic alfalfa lines approaches that used in these bioassays. Therefore, a sufficient concentration of RGluc should be available to inhibit pathogen ingress and reduce disease symptoms.
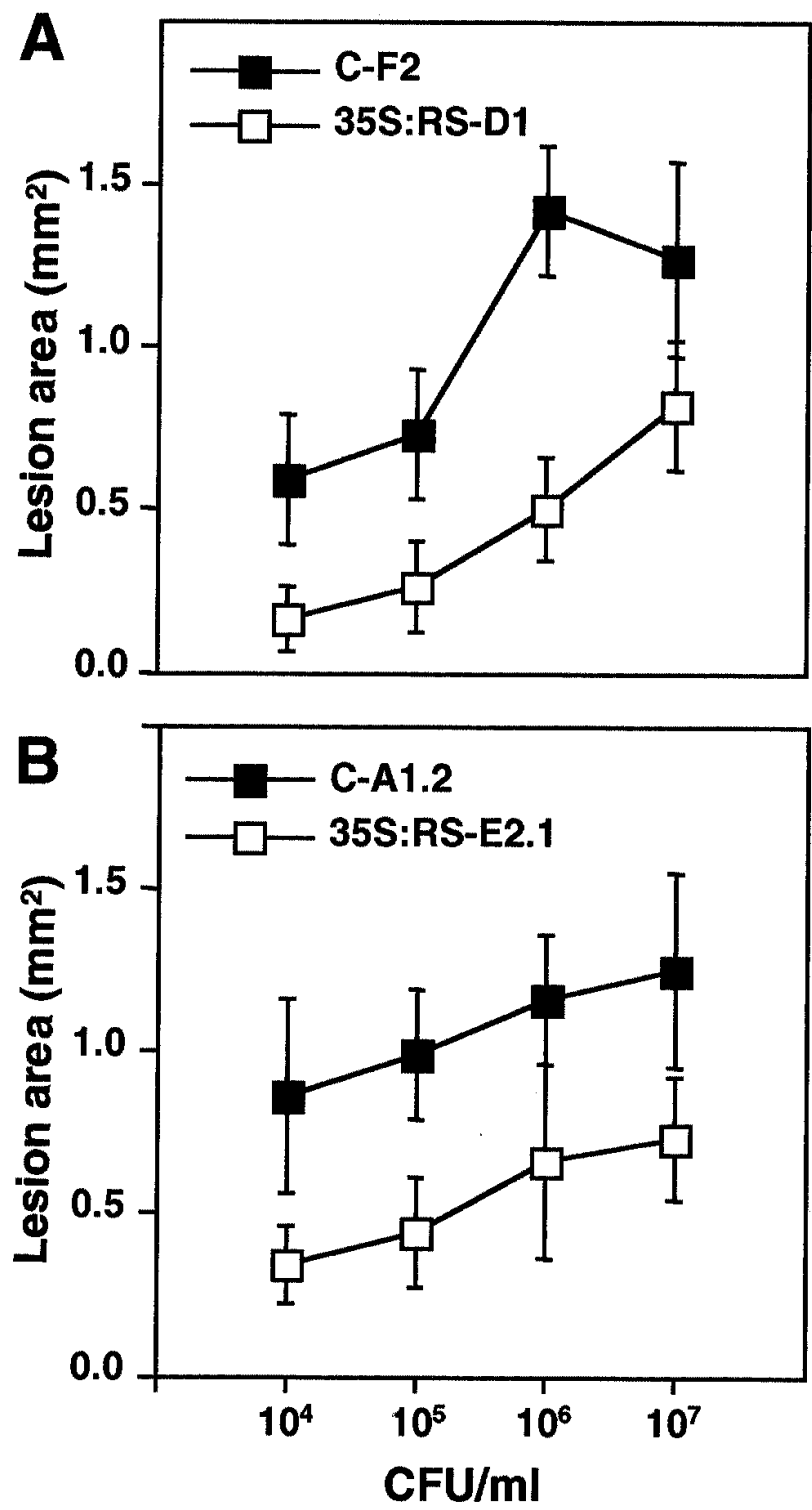

Fig. 8. Quantitation of necrotic lesion area in control and trans-resveratrol-3-O- $\beta$-D-glucopyranoside (RGluc)-accumulating leaves after wound inoculation with Phoma medicaginis. A and $\mathbf{B}$, Two independently transformed Cauliflower mosaic virus (CaMV) 35S:RS (resveratrol synthase) lines (35S:RS-D1 and 35S:RS-E2.1) and two pGA482 vector control lines (C-F2 and C-A1.2) showing average necrotic lesion size $\left(\mathrm{mm}^{2}\right)$ surrounding wound site at four different $\mathrm{CFU} / \mathrm{ml}$, measured at 10 days post inoculation. Error bars represent standard deviation of the mean.
Two independent alfalfa lines that consistently accumulate the highest levels of RGluc and two independent pGA482 vector control lines were tested for resistance to $P$. medicaginis. First and second trifoliate leaves (Fig. 4) were wound inoculated with small-gauge needles that had been dipped in spore suspensions varying from $10^{4}$ to $10^{7} \mathrm{CFU}$ per ml. After 10 days, the brown necrotic zone surrounding
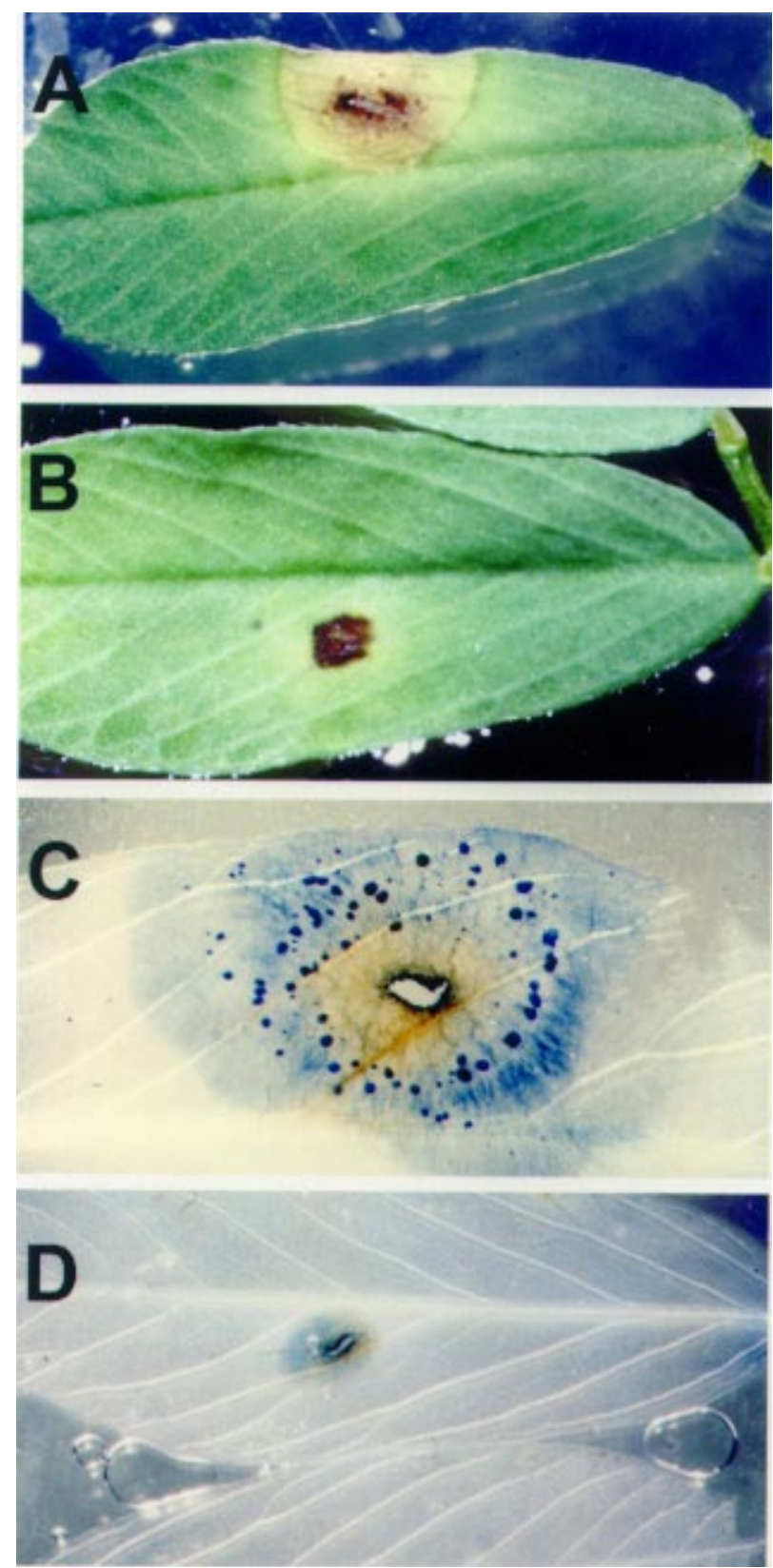

Fig. 9. Development of chlorotic zone and fungal reproductive structures (pycnidia) in alfalfa leaves. A, A pGA482 vector control transgenic alfalfa leaf showing symptoms development at 10 days post wound inoculation with the alfalfa pathogen Phoma medicaginis, compared with (B) response in a Cauliflower mosaic virus (CaMV) 35S:RS (resveratrol synthase)-transformed line that accumulates high levels of trans-resveratrol-3-O- $\beta$-D-glucopyranoside (RGluc). C, Trypan blue staining of the wound-inoculated pGA482 vector control line, compared with (D) a CaMV 35S:RS line. Pycnidia (dark blue globular structures) and fungal mycelia are clearly visible in the infected vector control leaves (C). 
the wound site was measured. Over the range of CFUs tested, the area $\left(\mathrm{mm}^{2}\right)$ of tissue necrosis was reduced on average by as much as $50 \%$, compared with the vector control plants (Fig. 8A and B). In addition, the observed area of chlorosis surrounding the necrotic zone also appeared to be greatly reduced (Fig. 9A and B).

Further evidence of increased resistance to $P$. medicaginis was found after the inoculated leaves $\left(10^{4} \mathrm{CFU} / \mathrm{ml}\right.$; Fig. $8 \mathrm{~A}$ and $\mathrm{B}$ ) were detached and allowed to incubate at $100 \%$ relative humidity. After 3 days, the leaves were stained with trypan blue in order to visualize the extent of hyphal ingress. Results in Figure 9C show extensive hyphal growth in the vector control line and the formation of reproductive structures (pycnidia). In contrast, only a small area of fungal hy-

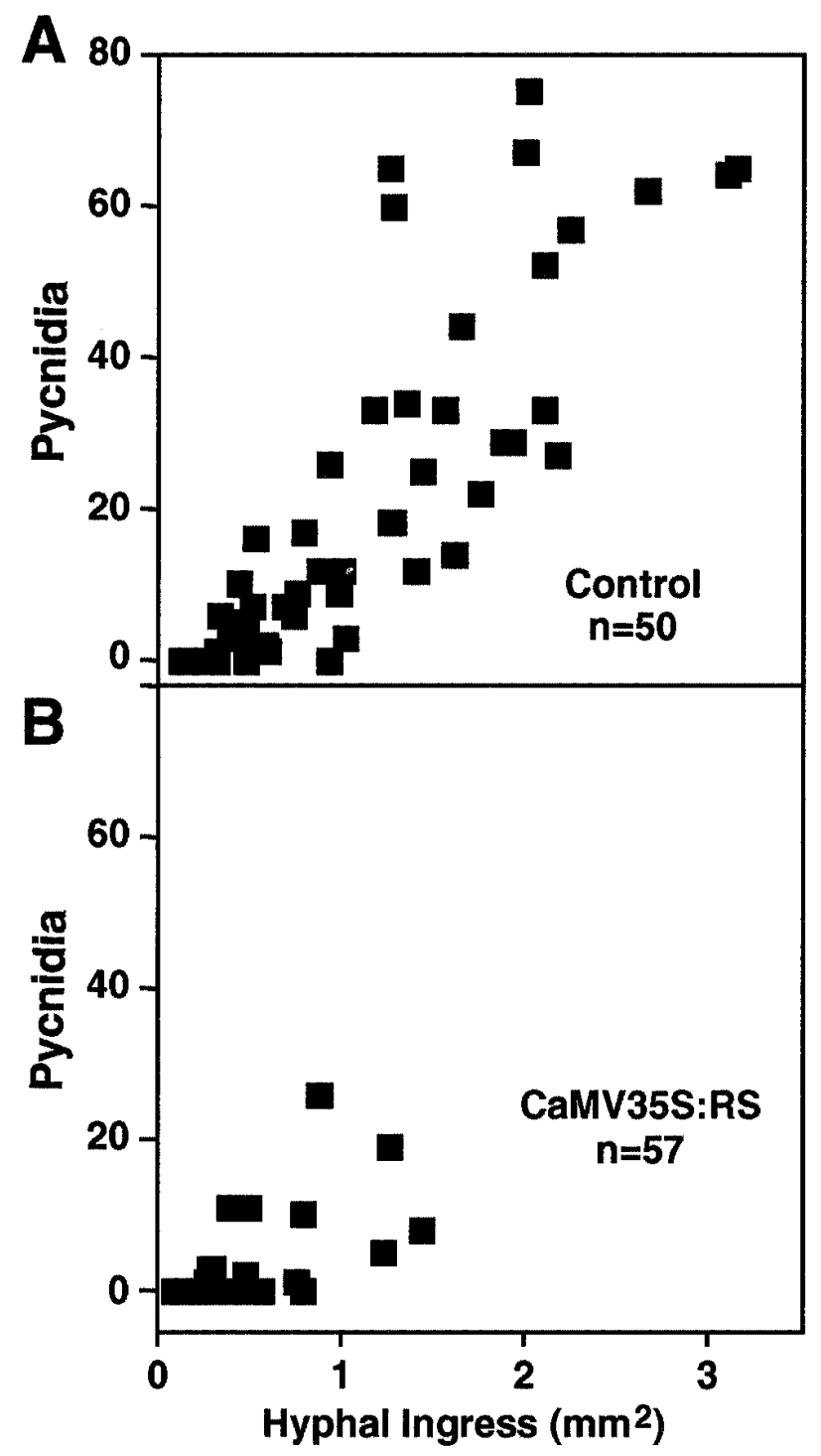

Fig. 10. Comparison of the extent of hyphal ingress to the number of pycnidia. Following trypan blue staining, total area of hyphal ingress was measured and number of pycnidia scored in inoculated leaves $\left(\mathrm{CFU} / \mathrm{ml}=10^{4}\right)$ from $(\mathbf{A})$ control and (B) Cauliflower mosaic virus (CaMV) 35S:RS (resveratrol synthase) lines at 8 and 10 days post inoculation, respectively. $\mathrm{n}=$ total number of lesions measured for control and CaMV 35S:RS lines $(n=50$ and $n=57$, respectively). phae (blue staining) outside of the necrotic zone could be observed in inoculated leaves from a CaMV 35S:RS transgenic line (Fig. 9D) and comparatively few pycnidia were observed. Similar results were also observed when these experiments were repeated and analyzed at 8 days post inoculation. Subsequently, the extent of hyphal ingress outside of the necrotic zone surrounding the wound site and the number of pycnidia were measured for a large number of leaves 8 and 10 days after infection. Results in Figure 10A and B clearly show that extent of hyphal ingress and number of pycnidia formed beyond the necrotic zone are much greater in the vector control lines than in the CaMV 35S:RS lines. In only 13 out of 57 lesions examined from the CaMV 35S:RS lines could pycnidia be identified, compared with 47 out of 50 lesions from the vector controls. Together, these experiments indicate that the accumulation of RGluc is sufficient to reduce the extent of leaf necrosis, prevent chlorosis caused by hyphal ingress, and substantially reduce the number of reproductive structures.

\section{DISCUSSION}

\section{Identification of RGluc in transgenic plants expressing RS.}

In this study, we successfully transformed and expressed a peanut RS cDNA, resulting in the accumulation of a novel foreign phytoalexin in transgenic alfalfa. To our knowledge, we are the first to report the accumulation of RGluc in any plant species transformed with an RS-encoding gene. In multiple previous investigations, the $R S$ gene (Vstl) from grapevine was transcriptionally regulated by its own fungal pathogen- and elicitor-inducible promoter (Hain et al. 1993; Thomzik et al. 1997; Stark-Lorenzen et al. 1997). The expected, localized activation of RS in response to pathogen attack is likely to result in the synthesis of resveratrol as an aglycone. Fischer et al. (1997) recently reported high levels of resveratrol (aglycone) in transgenic tobacco leaves constitutively expressing $R S$ under the control of a CaMV $35 \mathrm{~S}$ promoter. However, these investigators primarily relied on an enzyme-linked immunosorbent assay (ELISA) to indirectly verify the accumulation of resveratrol. Inducible expression of $R S$ in the monocot rice resulted in reduced disease symptoms, but the accumulation of resveratrol could not be detected by ELISA (Stark-Lorenzen et al. 1997). It is unknown whether the resveratrol-glucoside we have identified would cross-react in this ELISA, thereby misleading previous researchers into reporting resveratrol aglycone accumulation, or if the glycosylation of resveratrol in our transgenic lines is unique to alfalfa. Only in the work by Hain et al. (1990) was free resveratrol conclusively identified by HPLC; fungal-elicited, transgenic, tobacco cell suspension cultures produced a peak that co-chromatographed with an authentic resveratrol standard. Based on observations of pterocarpan phytoalexins and other phenolic natural products, it appears that constitutively accumulated phenolics are often glycosylated, while rapidly synthesized, pathogen-induced pools are often unconjugated (Stafford and Ibrahim 1992). The conjugation of glucose to resveratrol may help protect the plant cells from its toxic effect, while at the same time it protects resveratrol from oxidation and enzymatic degradation. 
The competition for metabolic intermediates, $p$-coumaroyl CoA and malonyl CoA, by high levels of apparent RS activity does not have any adverse effect on the normal growth and development of our transgenic alfalfa lines. Thus far, experiments with alfalfa lines that accumulate the highest levels of RGluc exhibit normal flower color, seed set, germination, and nodulation, compared with the wild type and vector control plants (data not shown). In addition, no RGluc could be detected by HPLC in transgenic alfalfa pollen extracts. This is in contrast to tobacco lines where constitutive expression of RS and high accumulation of resveratrol result in male-sterility and the loss of flower pigment (Fischer et al. 1997). However, in tobacco, fertility could be restored by the exogenous application of flavonols, suggesting that the RS depleted metabolic intermediates required by CHS, arresting pollen development; it is unknown whether or not alfalfa requires flavonols for pollination. The pattern of RGluc accumulation in the leaves and internodes that we have observed (Fig. 5A) may be related to flavonoid synthesis in young leaves (Wiermann 1981) and increased lignin accumulation in older internodes (Inoue et al. 1998). For example, the active biosynthesis of flavonoids and lignin during growth and development would require available pools of $p$-coumaroyl CoA, and activation of early phenylpropanoid genes in these tissues would provide precursor for both these products and resveratrol. In contrast, we believe that the absence of RGluc accumulation in the roots of the transgenic lines is, at least in part, due to high competition from chalcone synthase (Fig. 6A and B). Therefore, the successful accumulation of RGluc is likely to be dependent upon a combination of sufficient RS levels and the availability of common substrates ( $p$-coumaroyl CoA and malonyl CoA), present due to the expression of endogenous phenylpropanoid pathways, while at the same time being in competition with other later pathway enzymes, such as those involved in isoflavonoid, flavonoid, anthocyanin, and lignin biosynthesis.

\section{Increased resistance to $P$. medicaginis in transgenic alfalfa expressing RS.}

The long-term goal of our experiments is to increase resistance of alfalfa to a wide array of foliar, stem, and root fungal pathogens. Alfalfa is not known to accumulate stilbenes; therefore, alfalfa fungal pathogens may not have evolved a mechanism for resisting the toxic effect of resveratrol. As a phytoalexin, resveratrol has been best characterized in Vitis spp., where it is believed to contribute significantly to resistance against fungal pathogens such as Botrytis cinerea, the causal agent of gray mold (for review see Dercks et al. 1995; Pezet and Pont 1995). Resistance to B. cinerea has also been reported in transgenic tobacco, wheat, and barley transiently expressing RS following inoculation (Hain et al. 1993; Leckband and Lörz 1998). In contrast, transgenic tomato lines were not resistant to $B$. cinerea or Alternaria solani; however, a significant increase in resistance was reported to Phytophthora infestans (Thomzik et al. 1997). The effectiveness of resveratrol as a phytoalexin has been questioned with the observation that $B$. cinerea isolated from Vitis spp. produce a laccase-like phenol oxidase capable of degrading resveratrol (Sbaghi et al. 1996; Adrian et al. 1998). The activity of this fungal enzyme results in the oxidation of trans-resveratrol to a resveratrol trans-dehydrodimer (Breuil et al. 1998). However, it is not inconceivable that Vitis spp. fungal pathogens might have evolved a mechanism to detoxify resveratrol after centuries of encountering this phytoalexin. Pathogens of alfalfa, which is not known to accumulate stilbenes as a defense response, could be encountering resveratrol for the first time in alfalfa transformed with RS, and are therefore much less likely to have evolved resistance.

Following wound inoculation, we have found that independent lines transformed with the CaMV 35S:RS construct exhibit reduced disease symptoms caused by $P$. medicaginis. Results from agar-plate bioassays suggest the RGluc can effectively inhibit hyphal growth of this pathogen. The conjugation of a glucose moiety has no apparent effect on the ability of resveratrol to inhibit hyphal growth (Fig. 7). We speculate that the fungal hyphae may produce a $\beta$-glucosidase that releases the resveratrol aglycone before or after the uptake of RGluc. The concentrations of RGluc (measured as resveratrol equivalents) used in these agar-plate bioassays are more than twofold higher than levels observed in the transgenic RSexpressing lines, assuming a uniform distribution in the tissues. Despite this, the inhibition of fungal development in the transgenic alfalfa leaves is much more striking than that observed on the agar media. This may be due to differing nutritional environments, or due to synergistic interactions of RGluc with other defense mechanisms present in alfalfa (e.g., hydrolytic enzymes, endogenous phytoalexins, $\mathrm{H}_{2} \mathrm{O}_{2}$ production, etc.).

In the field, infection with $P$. medicaginis results in the appearance of necrotic spots, spreading chlorosis, and subsequent leaf drop, causing a significant loss of yield and forage quality during spring haying seasons (Leath 1990). In our experiments, we have observed the formation of fungal reproductive structures known as pycnidia on detached infected leaves. Importantly, the pycnidia do not form within the necrotic zone observed in either the CaMV 35S:RS or pGA482 vector control lines (Fig. 9C and D). Our results strongly suggest that RGluc concentrations identified in these transgenic lines are sufficient to prevent significant pathogen spread beyond this necrotic zone and, therefore, the number of reproductive structures formed is greatly reduced (Fig. 10B). Limitation of the spread of disease from a primary infection site has important implications in the disease cycle and epidemiology of this organism. Use of transgenic alfalfa lines accumulating RGluc in the field may reduce $P$. medicaginis infestation and improve forage production. Consumption of alfalfa containing RGluc by ruminants (or by humans consuming suitably transformed alfalfa sprouts) is unlikely to cause any detrimental side effects; flavonoid conjugates have been shown to be degraded by the rumen microflora, and humans have been consuming RGluc and free resveratrol for centuries in the form of grapes and wine, with apparently beneficial effects (Jang et al. 1997; Soleas et al. 1997).

At the present time, we are testing these same lines against other alfalfa pathogens such as Colletotrichum trifolii and Leptosphaerulina briosiana, as well as isolates of Fusarium spp., and Verticillium spp., which also showed sensitivity to resveratrol in agar-plate bioassays. We are also investigating alternative expression strategies, such as stronger promoters, to allow higher RGluc accumulation in 
the roots, as a means of possibly providing protection against sensitive root pathogens.

\section{MATERIALS AND METHODS}

\section{Plant material and greenhouse conditions.}

Alfalfa (Medicago sativa L.) cv. Regen SY (Bingham 1991) stocks and transgenic lines were maintained in MetroMix 350 in greenhouse conditions under a 16-h photoperiod, at 25 to $30^{\circ} \mathrm{C}, 40$ to $60 \%$ humidity (The Scotts Co., Marysville, $\mathrm{OH}$ ). Independent transgenic lines were vegetatively propagated by cuttings, dipped in a $0.3 \%$ indolebutryic acid root powder, planted in MetroMix 350, and held in growth chambers (Conviron, Winnipeg, Manitoba, Canada) under a 16-h photoperiod with $100 \%$ relative humidity for 3 weeks. For root analysis, cuttings were grown either in the greenhouse in Metromix 350 or in a growth chamber $\left(20^{\circ} \mathrm{C}\right)$ in perlite wetted with a low nitrogen nutrient solution-1 $\mathrm{mM} \mathrm{KNO}_{3}, 2 \mathrm{mM}$ $\mathrm{MgSO}_{4}, 1 \mathrm{mM} \mathrm{K} \mathrm{SO}_{4}, 1 \mathrm{mM} \mathrm{K} \mathrm{HPO}_{4}$ (pH 6.8), $0.344 \mathrm{~g}$ of $\mathrm{CaSO}_{4} \cdot 2 \mathrm{H}_{2} \mathrm{O}$ per liter, $8.6 \mu \mathrm{g}$ of FeNaEDTA $2 \mathrm{H}_{2} \mathrm{O}$ per liter, and micronutrients as in Johnson et al. (1957)—inoculated with Rhizobium meliloti.

\section{Vector constructs and plant transformation.}

The peanut (Arachis hypogaea) RS cDNA (Tropf et al. 1994) was subcloned into the NcoI and BamHI sites of a CaMV 35S dual enhancer promoter/3' end cassette pRTL2 (Restrepo et al. 1990). The CaMV 35S:RS cassette was partially digested with HindIII and subcloned into the HindIII site of the binary vector pGA482 (An 1986). Restriction enzyme digest and DNA sequencing confirmed the integrity of the construct. The binary vector and vector constructs were maintained in Escherichia coli DH5 $\alpha$ (Clontech, Palo Alto, CA) and transferred by electroporation to Agrobacterium tumefaciens LBA4404.

Transgenic alfalfa plants were generated from a single parent plant of the transformation- and regenerationcompetent alfalfa cultivar Regen SY (Bingham 1991) following a modified version of published procedures. Alfalfa plants were transformed with A. tumefaciens LBA4404 harboring either the pGA482 (control) or the CaMV 35S:RS construct by the leaf disk method with regeneration under kanamycin selection (Bingham et al. 1975; Oommen et al. 1994). Surviving plantlets were placed on MS media without selection (Murashige and Skoog 1962) for an additional month before transfer to Magenta boxes (Magenta, Chicago) and subsequent axenic propagation by vegetative cuttings. Rooted cuttings were transferred to MetroMix 350, placed on a misting bench for 1 week, and finally placed under greenhouse conditions.

\section{Southern blot and PCR analyses of transgenic lines.}

Genomic DNA was extracted from $1 \mathrm{~g}$ of alfalfa green leaf tissue as described (Dellaporta et al. 1983). Twenty micrograms of DNA was digested with HindIII and size fractionated by $1 \%$ agarose gel electrophoresis (Sambrook et al. 1989). The gel was treated in $0.25 \mathrm{M} \mathrm{HCl}(10 \mathrm{~min})$, denatured with $0.5 \mathrm{M} \mathrm{NaOH} / 1.0 \mathrm{M} \mathrm{NaCl}(20 \mathrm{~min})$ and neutralized with $0.5 \mathrm{M}$ Tris- $\mathrm{HCl} / 1.5 \mathrm{M} \mathrm{NaCl}(20 \mathrm{~min})$ with gently shaking, then transferred overnight by capillary action to a nylon membrane (GeneScreen Plus; DuPont, Boston) in 5x SSPE (1× SSPE is
$0.15 \mathrm{M} \mathrm{NaCl}, 10 \mathrm{mM}$ sodium phosphate, $1 \mathrm{mM}$ EDTA, $\mathrm{pH}$ 7.4). The DNA was covalently crosslinked to the membrane by ultraviolet light (Stratalinker; Stratagene, La Jolla, CA). The hybridization probe was prepared by digesting the pGA482 binary vector with BamHI and HindIII to release a fragment of the NPTII gene. The gel-purified fragment was labeled with ${ }^{32} \mathrm{P}-\mathrm{dCTP}$ by the random primer method (Primea-Gene; Promega, Madison, WI). Southern hybridizations were carried out by the method of Church and Gilbert (1984) at $65^{\circ} \mathrm{C}$. Copy number and independent transformants were subsequently identified by the border analysis hybridization pattern. For this report, all independent transgenic plants contained only one copy of the transgene cassette (data not shown).

To identify those independent transgenic lines that successfully integrated the full-length coding region, RS cDNA specific primers (5' CCATGGAAGGGGGAATTCGC $\left.3^{\prime}\right)$ and (5' GAGCCATTCAGCACCTTAGC $3^{\prime}$ ) were used in PCRs. One to two micrograms of genomic DNA was combined with 0.4 $\mu \mathrm{M}$ (final concentration) primers, $10 \mathrm{mM}$ dNTPs, $1 \mathrm{U}$ of Taq DNA polymerase (Promega), in $1 \times$ PCR buffer adjusted to a final volume of $50 \mu \mathrm{l}$. The binary vector construct used in the transformation protocol served as a positive control reaction. Thermocycler (Singleblock System; Ericomp, San Diego, CA) conditions were as follows: denature at $95^{\circ} \mathrm{C}$ for $2 \mathrm{~min}$, anneal at $55^{\circ} \mathrm{C}$ for $1.3 \mathrm{~min}$, elongate at $72^{\circ} \mathrm{C}$ for $2 \mathrm{~min}$, for a total of 30 cycles, followed by a final elongation of $15 \mathrm{~min}$ at $72^{\circ} \mathrm{C}$. Twenty-five microliters of PCR products was separated by agarose gel electrophoresis and visualized by ethidium-bromide staining under UV light.

\section{Northern blot analyses of RS and CHS transcript levels.}

Total RNA was extracted from the leaves, internodes, or roots by the method of Logemann et al. (1987). However, after overnight precipitation, the protocol was modified such that the RNA was purified from the aqueous phase by the method of Zhou and Goldsbrough (1993). The RNA (10 $\mu \mathrm{g}$ per lane) was size fractionated by $1 \%$ agarose-formaldehyde gel electrophoresis by the method of Sambrook et al. (1989). The RNA was transferred overnight by capillary action to a nylon membrane (GeneScreen Plus; DuPont) in 5× SSPE. The hybridization conditions and radiolabeling of probes were prepared as described above. For individual experiments, probes included an RS cDNA from peanut (Tropf et al. 1994) and a CHS cDNA (Junghans et al. 1993); all membranes were later hybridized with a soybean $18 \mathrm{~S}$ ribosomal RNA probe (Eckenrode et al. 1985) as a loading control.

\section{Characterization and RGluc identification by HPLC analysis.}

Independent transgenic alfalfa lines harboring the CaMV $35 \mathrm{~S}: \mathrm{RS}$ construct were analyzed for the presence of resveratrol by reverse-phase C18 HPLC analysis $(4.6 \times 250$ mm column; J. T. Baker, Phillipsburg, NJ). Metabolites were extracted from 0.5 to $1.0 \mathrm{~g}$ of fresh leaves, internodes, or roots in $100 \%$ acetone for up to 2 days. The supernatant was dried completely under nitrogen and dissolved in $0.7 \mathrm{ml}$ of methanol followed by $0.3 \mathrm{ml}$ of water. The sample was vortexed vigorously, sonicated for $5 \mathrm{~min}$, then centrifuged to remove the insoluble debris. The final supernatant was concentrated to dryness then dissolved in $0.1 \mathrm{ml}$ of methanol. 
For analysis, $20 \mu \mathrm{l}$ of sample was injected and metabolites separated by a 45 -min linear gradient from 20 to $60 \%$ solvent $\mathrm{B}$ (solvent $\mathrm{A}=1.0 \% \mathrm{H}_{3} \mathrm{PO}_{4}$, solvent $\mathrm{B}=100 \%$ acetonitrile) with a flow rate of $0.8 \mathrm{ml} / \mathrm{min}$ monitored at $\lambda=$ $320 \mathrm{~nm}$. UV spectra of peaks of interest were recorded with a UV diode array detector (Beckman Instruments, Fullerton, $\mathrm{CA})$. Characterization of the putative resveratrol-conjugate was performed by $\beta$-glucosidase digestion of a crude leaf extract. The methanol was removed under nitrogen and the residue dissolved in $200 \mu \mathrm{l}$ of $25 \mathrm{mM}$ citric acid/phosphate buffer ( $\mathrm{pH} 5.2$ ) containing $0.5 \mathrm{mg}$ of $\beta$-glucosidase from almonds per ml (Sigma Chemical, St. Louis, MO). After incubation at $37^{\circ} \mathrm{C}$ for $1 \mathrm{~h}$, the free resveratrol was extracted from the aqueous phase with an equal volume of ethyl acetate three times. The ethyl acetate extracts were pooled and concentrated to dryness under nitrogen, dissolved in methanol, then analyzed by HPLC. The identity of resveratrol was confirmed by co-chromatography with a resveratrol standard (Sigma Chemical) and by comparison of UV absorbance spectra.

\section{${ }^{1} \mathrm{H}$ - and ${ }^{13} \mathrm{C}$-NMR analyses of RGluc.}

The suspected resveratrol-glucose conjugate was purified from several kilograms of transgenic alfalfa leaves and internode tissue. Large volumes of crude acetone extracts were concentrated to near dryness under vacuum. Insoluble materials were removed by centrifugation with the remaining supernatant adjusted to $50 \%$ methanol. To remove highly lipophilic substances, the extract was passed over C18 reverse-phase disposable cartridges (SepPak; Waters, Milford, MA) followed by concentration to near dryness under vacuum to remove the methanol. The aqueous phase was extracted three times with an equal volume of ethyl acetate. The ethyl acetate fractions were pooled and concentrated to dryness under vacuum. The final residue was dissolved in methanol. The resveratrol-conjugate was then purified by preparative C18 reverse-phase HPLC $(22.5 \times 250 \mathrm{~mm}$, Econosil; Alltech, Deerfield, IL). For purification, $0.5 \mathrm{ml}$ of extract was separated by a 45-min linear gradient from 10 to $25 \%$ solvent $\mathrm{B}$ (solvent $\mathrm{A}=$ water, solvent $\mathrm{B}=$ acetonitrile) at a flow rate of $20 \mathrm{ml} / \mathrm{min}$ monitored at $\lambda=320 \mathrm{~nm}$. Fractions containing the resveratrol conjugate were pooled, concentrated to dryness under nitrogen, and purified a second time. The final fraction was concentrated to dryness and dissolved in a small volume of methanol. The concentration was estimated by comparison of the absorbance spectra to a known concentration of the resveratrol standard. The sample to be analyzed was dried under nitrogen and analyzed by ${ }^{13} \mathrm{C}-\mathrm{NMR}$ (150 MHz, CD $\left.30 \mathrm{OD}\right)$ and ${ }^{1} \mathrm{H}-\mathrm{NMR}$ (600 MHz, $\mathrm{CD}_{3} \mathrm{OD}$ ). Identity of the compound was confirmed by comparison to previously published reports (Mattivi et al. 1995; Teguo et al. 1996).

\section{Agar-plate bioassay and plant-pathogen interactions.}

The alfalfa fungal pathogen Phoma medicaginis Malbr. \& Roum. var. medicaginis was maintained on potato dextrose agar (PDA; Difco Laboratories, Detroit, MI ) for 1 month in a dark growth chamber at $22^{\circ} \mathrm{C}$ (see Blount et al. 1993). Agarplate bioassays were performed by dissolving resveratrol or RGluc purified from transgenic alfalfa lines in $50 \mu \mathrm{l}$ of ethanol. The concentration of RGluc (measured in resveratrol equivalents) was estimated by HPLC analysis and comparison to a known concentration of a resveratrol standard. The ethanol solution was added to molten PDA such that the final concentrations of resveratrol or RGluc was $50 \mu \mathrm{g} / \mathrm{ml}$. For this experiment, control plates were made whereby an equal volume of ethanol was added to PDA without resveratrol. A small agar plug of $P$. medicaginis was placed in a petri dish containing the resveratrol-PDA mixture, sealed with Parafilm, and placed in a dark grown chamber at $22^{\circ} \mathrm{C}$. The extent of hyphal growth was measured after 1 week.

To test for resistance in the transgenic lines, the first and second trifoliate leaves of greenhouse-grown transgenic alfalfa lines were wound inoculated with a 27.5 -gauge syringe needle dipped in a $P$. medicaginis spore suspension. The number of CFU per ml was estimated by plating a serial dilution of the spore suspension on PDA. After inoculation, the stem was cut at the fourth internode and placed in a clear plastic box (Magenta, Chicago), with the cut end embedded in $0.8 \%$ water agar (Phytagar, Difco). The Magenta box was sealed with Parafilm to maintain $100 \%$ humidity and placed in a growth room (16-h photoperiod, $22^{\circ} \mathrm{C}$ ) where disease symptoms were allowed to develop for 8 to 10 days. The extent of necrosis around the wound sites was measured with a digital video imaging system (Ultra-Lum, Paramount, CA) and analysis software (Scion Image for Windows, Frederick, MD).

To determine the extent of hyphal growth and the formation of reproductive structures, excised leaves were placed in $100 \%$ humidity for up to 3 days followed by training with a trypan blue/ethanol solution (Keogh et al. 1980). Briefly, the leaves were completely covered with the trypan blue staining solution $(10 \mathrm{ml}$ of lactic acid; $10 \mathrm{ml}$ of Tris-equilibrated phenol, $\mathrm{pH} 7.4 ; 10 \mathrm{ml}$ of glycerol; $10 \mathrm{ml}$ of water; $10 \mathrm{mg}$ of trypan blue, Sigma) followed by an equal volume of $100 \%$ ethanol. The samples were boiled for $5 \mathrm{~min}$ then allowed to cool at room temperature for up to $24 \mathrm{~h}$. For destaining, the staining solution was discarded, $0.8 \mathrm{~g}$ of chloral hydrate per $\mathrm{ml}$ was added, followed by boiling for $3 \mathrm{~min}$. The chloral hydrate was discarded; the leaves were rinsed well with water and stored in $50 \%$ glycerol solution. Fungal hyphae and pycnidia were examined with a dissecting microscope (Model SMZ-10; Nikon, Tokyo) and photographed with Ektachrome 160T color slide film (Eastman Kodak, Rochester, NY) with a Nikon FX35WA $35 \mathrm{~mm}$ camera.

\section{ACKNOWLEDGMENTS}

We would like to thank Joachim Schröder, University of Freiburg, for providing the peanut RS cDNA and helpful discussion, Jim Carrington, Washington State University, for providing the pRTL2 double CaMV $35 \mathrm{~S}$ promoter construct. NMR spectra were obtained by Feng Qui at the Oklahoma Statewide Shared Nuclear Magnetic Resonance Facility, Oklahoma State University, Stillwater. We would like to thank Madan Bhattacharyya, Melina Lopez-Meyer, and Suparna Mundodi for critical review of the manuscript, and Cuc Ly, Broderick Stearns, and Allyson Wilkins for assistance with figures and manuscript preparation. This work was funded by the Samuel Roberts Noble Foundation, Ardmore, Oklahoma.

\section{LITERATURE CITED}

Adrian, M., Rajaei, H., Jeandet, P., Veneau, J., and Bessis, R. 1998. Resveratrol oxidation in Botrytis cinerea conidia. Plant Pathol. 88:472476. 
An, G. 1986. Development of plant promoter expression vectors and their use for analysis of differential activity of nopaline synthase promoter in transformed tobacco cells. Plant Physiol. 81:86-91.

Bingham, E. T. 1991. Registration of alfalfa hybrid Regen-SY germplasm for tissue culture and transformation research. Crop Sci. 31: 1098.

Bingham, E. T., Hurley, L. V., Kaatz, D. M., and Saunders, J. W. 1975. Breeding alfalfa which regenerates from callus tissue in culture. Crop Sci. 15:719-721.

Blount, J. W., Dixon, R. A., and Paiva, N. L. 1993. Stress responses in alfalfa (Medicago sativa L.) XVI. Antifungal activity of medicarpin and its biosynthetic precursors; implications for the genetic manipulation of stress metabolites. Physiol. Mol. Plant Pathol. 41:333-349.

Breuil, A.-C., Adrian, M., Pirio, N., Meunier, P., Bessis, R., and Jeandet, P. 1998. Metabolism of stilbene phytoalexins by Botrytis cinerea: characterization of a resveratrol dehydrodimer. Tetrahedron Lett. 39: 537-540.

Church, G. M., and Gilbert, W. 1984. Genomic sequencing. Proc. Natl. Acad. Sci. USA 81:1991-1994.

Dellaporta, S. L., Wood, J., and Hicks, J. B. 1983. A Plant DNA Minipreparation: Version II. Plant Mol. Biol. Rep. 1(4):19-21.

Dercks, W., Creasy, L., and Lucka-Bayles, C. J. 1995. Stilbene phytoalexins and disease resistance in Vitis. Pages 287-315 in: Handbook of Phytoalexin Metabolism and Action. M. Daniel and R. P. Purkayastha, eds. Marcel Dekker, New York.

Dixon, R. A., and Paiva, N. L. 1995. Stress-induced phenylpropanoid metabolism. Plant Cell 7:1085-1097.

Eckenrode, V. K., Arnold, J., Meagher, R. B. 1985. Comparison of the nucleotide sequence of soybean 18S rRNA with the sequences of other small-subunit rRNAs. J. Mol. Evol. 21:259-269.

Fischer, R., Budde, I., and Hain, R. 1997. Stilbene synthase gene expression causes changes in flower colour and male sterility in tobacco. Plant J. 11:489-498.

Grotewold, E., Chamberlin, M., Snook, M., Siame, B., Butler, L., Swenson, J., Maddock, S., St. Clair, G., and Bowen, B. 1998. Engineering secondary metabolism in maize cells by ectopic expression of transcriptional factors. Plant Cell 10:721-740.

Hahlbrock, K., and Scheel, D. 1989. Physiology and molecular biology of phenylpropanoid metabolism. Annu. Rev. Plant Physiol. Plant Mol. Biol. 40:347-369.

Hain, R., Bieseler, B., Kindl, H., Schröder, G., and Stöcker, R. 1990. Expression of a stilbene synthase gene in Nicotiana tabacum results in synthesis of the phytoalexin resveratrol. Plant Mol. Biol. 15:325335.

Hain, R., Reif, H.-J., Krause, E., Langebartels, R., Kindl, H., Vornam, B., Wiese, W., Schmelzer, E., Schreier, P., Stöcker, R., and Stenzel, K 1993. Disease resistance results from foreign phytoalexin expression in a novel plant. Nature 361:153-156.

Inoue, K., Sewalt, V., Balance, G. M., Ni, W., Sturzer, C., and Dixon, R.A. 1998. Developmental expression and substrate specificities of alfalfa caffeic acid 3-O-methyltransferase and caffeoyl coenzyme A 3$O$-methyltransferase in relation to lignification. Plant Physiol. 117: 761-770.

Jang, M., Cai, L., Udeani, G., Slowing, K., Thomas, C., Beecher, C., Fong, H., Farnsworth, N., Kinghorn, D., Mehta, R., Moon, R., and Pezzuto, J. M. 1997. Cancer chemopreventive activity of resveratrol, a natural product derived from grapes. Science 275:218-220.

Johnson, C. M., Stout, P. R., Bouyer, T. C., and Carlson, A. B. 1957. Comparative chloride requirements of different plants. Plant Soil 8: 337-353.

Junghans, H., Dalkin, K., and Dixon, R. A. 1993. Stress responses in alfalfa (Medicago sativa L.). 15. Characterization and expression patterns of members of a subset of the chalcone synthase multigene family. Plant Mol. Biol. 22:239-253.

Keogh, R. C., Deverall, B. J., and McLeod, S. 1980. Comparison of histological and physiological responses to Phykospora pachyrhizi in resistant and susceptible soybeans. Trans. Br. Mycol. Soc. 74:329333.

Langcake, P., and Pryce, R. J. 1976. The production of resveratrol by Vitis vinifera and other members of the Vitaceae as a response to infection or injury. Physiol. Plant Pathol. 9:77-86.

Lanz, T., Schroder, G., and Schroder, J. 1990. Differential regulation of genes for resveratrol synthase in cell cultures of Arachis hypogaea L. Planta 181:169-175.
Leath, K. 1990. Spring black stem and leaf spot. Pages 16-17 in: Compendium of Alfalfa Diseases. 2nd ed. D. Stuteville and D. C. Erwin, eds. American Phytopathological Society, St. Paul, MN.

Leckband, G. and Lörz, H. 1998. Transformation and expression of a stilbene synthase gene of Vitis vinifera L. in barley and wheat for increased fungal resistance. Theor. Appl. Genet. 96:1004-1012.

Logemann, J., Schell, J., and Willmitzer, L. 1987. Improved method for the isolation of RNA from plant tissues. Anal. Biochem.163:16-20.

Mannila, E., Talvittie, A., and Kolehmainen, E. 1993. Anti-leukaemic compounds derived from stilbenes in Picea abies bark. Phytochemistry 33:813-816.

Mattivi, F., Reniero, F., and Korhammer, S. 1995. Isolation, characterization, and evolution in red wine vinification of resveratrol monomers. J. Agric. Food Chem. 43:1820-1823.

Murashige, T. and Skoog, F. 1962. A revised media for rapid growth and bioassay with tobacco tissue culture. Physiol. Plant. 15:473-497.

Ni, W., Paiva, N. L., and Dixon, R. A. 1994. Reduced lignin in transgenic plants containing a caffeic acid $O$-methyltransferase antisense gene. Transg. Res. 3:120-126.

Oommen, A., Dixon, R. and Paiva, N. L. 1994. The elicitor-inducible alfalfa isoflavone reductase promoter confers different patters of developmental expression in homologous and heterologous transgenic plants. Plant Cell 6:1789-1803.

Paiva, N. L., Edwards, R., Sun, Y., Hrazdina, G., and Dixon, R. A. 1991. Stress responses in alfalfa (Medicago sativa L.) XI. Molecular cloning and expression of alfalfa isoflavone reductase, a key enzyme of isoflavonoid phytoalexin biosynthesis. Plant Mol. Biol. 17:653-667.

Paiva, N. L., Oommen, A., Harrison, M. J., and Dixon, R. A. 1994. Regulation of isoflavonoid metabolism in alfalfa. Plant Cell, Tissue Organ Culture 38:213-220. (Also published in Primary and Secondary Metabolism of Plants and Cell Cultures III [1995], J. Schripsema and R. Verpoorte, eds., Kluwer Academic Publishers, Boston, pp. 213220.)

Pezet, R., and Pont, V. 1995. Mode of toxic action of Vitaceae stilbenes on fungal cells. Pages 317-331 in: Handbook of Phytoalexin Metabolism and Action. M. Daniel and R. P. Purkayastha, eds. Marcel Dekker, New York.

Powell, R., TePaske, M., Plattner, R., White, J., and Clements, S. L. 1994. Isolation of resveratrol from Festuca versuta and evidence of the widespread occurrence of this stilbene in the Poaceae. Phytochemistry 35:335-338

Restrepo, M. A., Freed, D. D., and Carrington, J. C. 1990. Nuclear transport of plant potyviral proteins. Plant Cell 2:987-98.

Rice-Evans, C. A., Miller, N. J., and Paganga, G. 1997. Antioxidant properties of phenolic compounds. Trends Plant Sci. 2:152-159.

Rolfs, C.-H., and Kindl, H. 1984. Stilbene synthase and chalcone synthase: two different constitutive enzymes in cultured cells of Picea excelsa. Plant Physiol. 75:489-492.

Sambrook, J., Fritsch, E. F., and Maniatis, T. A. 1989. Molecular Cloning: A Laboratory Manual. 2nd ed. Cold Spring Harbor Laboratory, Cold Spring Harbor, NY.

Sbaghi, M., Jeandet, P., Bessis, R., and Leroux, P. 1996. Degradation of stilbene phytoalexins in relation to the pathogenicity of Botrytis cinerea to grapevines. Plant Pathol. 45:139-144.

Soleas, G. J., Diamandis, E. P., and Goldberg, D. M. 1997. Wine as a biological fluid: History, production, and role in disease prevention. J. Clin. Lab. Anal. 11:287-313.

Sotheeswaran, S., and Pasupathy, V. 1993. Distribution of resveratrol oligomers in plants. Phytochemistry 32:1083-1092.

Stafford, H. A., and Ibrahim, R. K., eds. 1992. Phenolic Metabolism in Plants. Plenum Press, New York.

Stark-Lorenzen, P., Nelke, B., Hänssler, G., Mühlbach, H., and Thomzik, J.E. 1997. Transfer of a grapevine stilbene synthase gene to rice (Oryza sativa L.. Plant Cell Rep. 16:668-673.

Sumner, L. W., Paiva, N. L., Dixon, R. A., and Geno, P. W. 1996. Highperformance liquid chromatography/continuous-flow liquid secondary ion mass spectrometry of flavonoid glucosides in leguminous plant extracts. J. Mass Spectrom. 31:472-485.

Teguo, P. W., Decendit, A., Vercauteren, J., Deffieux, G., and Mérillon, J.-M. 1996. Trans-resveratrol-3-O- $\beta$-glucoside (piceid) in cell suspension cultures of Vitis vinifera. Phytochemistry 42:1591-1593.

Thomzik, J., Stenzel, K., Stöcker, R., Schreier, P.H., Hain, R., and Stahl, D. 1997. Synthesis of a grapevine phytoalexin in transgenic tomatoes (Lycopersicon esculentum Mill.) conditions resistance against Phy- 
tophthora infestans. Physiol. Mol. Plant Pathol. 51:265-278.

Tropf, S., Lanz, T., Rensing, S., Schröder, J., and Schröder, G. 1994. Evidence that stilbene synthases have developed from chalcone synthases several times in the course of evolution. J. Mol. Evol. 38:610618.

Waterhouse, A. L., and Lamuela-Raventóst, R. M. 1994. The occurrence of piceid, a stilbene glucoside in grape berries. Phytochemistry 37:
571-573.

Wiermann, R. 1981. Secondary Plant Products and Cell and Tissue Differentiation. Pages 85-116 in: The Biochemistry of Plants. P. K. Stumpf and E. E. Conn, eds. Academic Press, New York.

Zhou, J., and Goldsbrough, P. B. 1993. An Arabidopsis gene with homology to glutathione S-transferase is regulated by ethylene. Plant Mol. Biol. 22:517-523. 